\title{
Electrochemical impedance spectroscopy (EIS) of composite polymer coatings on metal substrates
}

\author{
V.A. Golovin,* S.A. Dobriyan and V.E. Kasatkin \\ A.N. Frumkin Institute of Physical Chemistry and Electrochemistry, Russian Academy \\ of Sciences, Leninsky pr. 31, 119071 Moscow, Russian Federation \\ *E-mail:golovin@rocor.ru
}

\begin{abstract}
The electrochemical properties of multilayer composite polymer coatings consisting of a Znfilled inhibited primer layer and an external insulating polymer coating are investigated by the EIS method. During long-term exposure in aggressive media, the kinetics of the properties of coatings obtained on corrosion-inert (Pt) and corrosion-active (mild steel St3) substrates were compared. It is shown that the impedance spectrum in the studied systems is determined by the imposition of two relaxation processes: high-frequency (HF), due to the processes of electrolyte transfer, and low-frequency (LF) associated with the Faraday process of undercoating corrosion of $\mathrm{Zn}$ powder in the primer layer or substrate corrosion. The frequencies of the HF process for all investigated composite coatings, including those applied to different substrates, are close, while the frequency of the LF process depends on the coating structure and the substrate type. It is shown that frequencies of LF processes at high exposure times in composite coatings with $\mathrm{Zn}$-protective primer on different substrates (mild steel St3 or Pt) are identical $(9.3 \mathrm{~Hz})$. This fact is the base for the conclusion that the Faraday process in both cases is the same and deals with corrosion of $\mathrm{Zn}$ powder. The coating structure is a factor determining the frequency of the LF process for coatings on a steel substrate. In composite systems with Zn-rich primer, the Faraday low-frequency process is observed at significantly lower frequencies $(9.3 \mathrm{~Hz})$ than in the case of applying only the insulating coating $(250 \mathrm{~Hz})$, not only at the initial stage, but also at high exposure times in $3 \% \mathrm{NaCl}$. This can be seen as evidence of prolonged protective action of the $\mathrm{Zn}$ powder in composite coatings. So the nature of the under-coating corrosion process can be determined by its EIS characteristic frequency.
\end{abstract}

Key words: electrochemical impedance spectroscopy, corrosion inhibitors, protective polymer coatings.

Received: November 30, 2018. Published: December 17, 2018

doi: $\underline{10.17675 / 2305-6894-2018-7-4-15}$

Zinc-rich primers [1] containing inhibiting additives [2] ensure a high anti-corrosive effectiveness as protective coatings in aggressive media.

However, primers are used, as a rule, as part of multi-layer composite coatings with upper insulating and specialized layers [3,4]. Such composite coatings are characterized by high diffusion resistance and the possibility of selective transfer of penetrating aggressive medium components [5]. Because of multi-layer composition and heterogeneity 
over thickness, their study and assessment of the mechanism of protective action are greatly complicated.

A complex study of the electrochemical properties kinetics during long-term exposure in aggressive media of the model composite coatings was carried out. The model composite coatings consisted of a primer layer with electrochemically active and inhibiting additives and the external layer of an insulating polymer coating that does not contain active additives.

\section{Objects and research methods}

The objects of research were both composite (2-layer) coatings consisting of an epoxy Znrich primer layer with an upper inert epoxy insulating layer, and the coatings consisting of an insulating layer only. The water-diluted epoxy Zn-rich primer Metacor-017 (M-017) with silicon-organic and nitrogen-containing inhibiting additives was used as a material for the primer layer, and the water-diluted epoxy enamel Rokor-5095 (R-5095) was used for the insulating layer [6]. The coatings were applied on the corrosion-active mild steel (GOST 380:2005 - St3kp (St3), ISO 630:1995 - E235-A (Fe 360-A)) and inert platinum (Pt) substrates.

Comparative studies of composite coatings on corrosion-active and inert substrates allow to separate the electrochemical and corrosion processes in the functional layers of the coating and on the surface of the substrate. Studies were conducted in a model of sea water $(3 \% \mathrm{NaCl})$ during 160 days.

Electrochemical impedance spectroscopy (EIS) in combination with potentiometry [7-9] was the main method of research. Both purely insulating coatings and composite coatings, including insulating layers, have very high resistances $\left(\sim 10^{6} \Omega\right)[10,11]$. This imposes additional requirements on the equipment and measurement methods [12-14]. A complete upgrade of the Frequency Response Analyzer (FRA) and software confirmed an acceptable level of measurement accuracy over the entire frequency range. The error in restoration for the elements of the model high-resistance equivalent circuits did not exceed $2 \%$ compared with the nominal values.

\section{Results and discussion}

The results in the form of the hodographs $\operatorname{Im}(Z)=f(\operatorname{Re}(Z))$ and the frequency dependences of the impedance module $|Z|$ and the phase angle $(\theta)$ for the various coatings on the various corrosivity substrates are shown below.

The results are considered according to the scheme:

1. The insulating coating on a corrosion-inert platinum $(\mathrm{Pt})$ substrate.

2. The insulating coating on a corrosion-active mild steel (St3) substrate.

3 . The coating consisting of an epoxy Zn-rich primer layer with overlapping upper insulating layer on an inert platinum $(\mathrm{Pt})$ substrate.

4. The coating consisting of an epoxy Zn-rich primer layer with overlapping upper insulating layer on a mild steel (St3) substrate. 
The results of studies with large exposure times are of the greatest interest for the purpose of this work.

\subsection{Impedance of an insulating coating on a corrosion-inert platinum substrate}

An insulating coating without active additives on an inert substrate is advisable to consider first (Figures 1, 2).
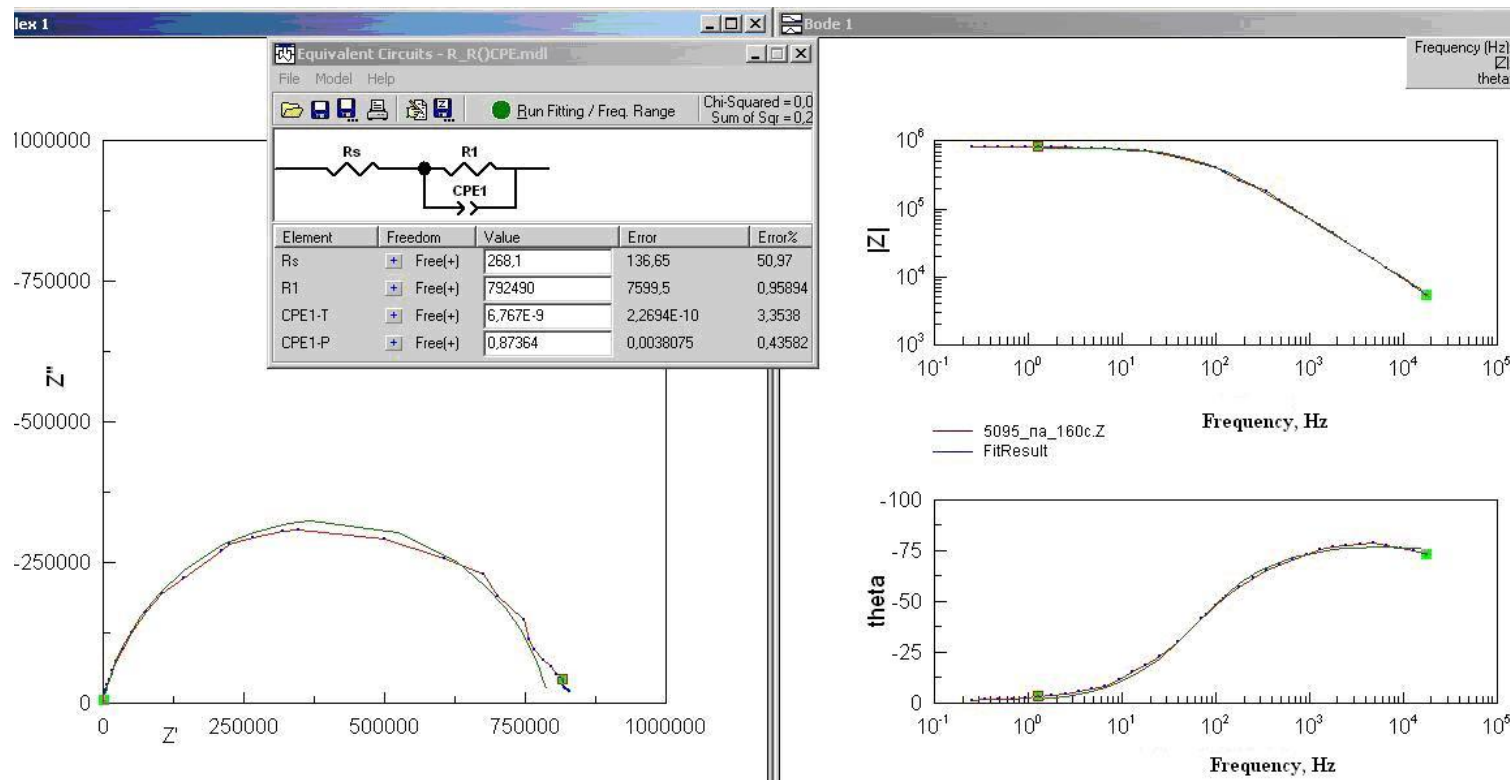

Figure 1. The hodograph and frequency dependences of the impedance of the R-5095 coating with inert filler $\left(\mathrm{TiO}_{2}\right)$ on a platinum substrate after exposure to $3 \% \mathrm{NaCl}$ for 160 days. Bode diagram maximum frequency is $5.7 \pm 1.0 \mathrm{kHz}$.

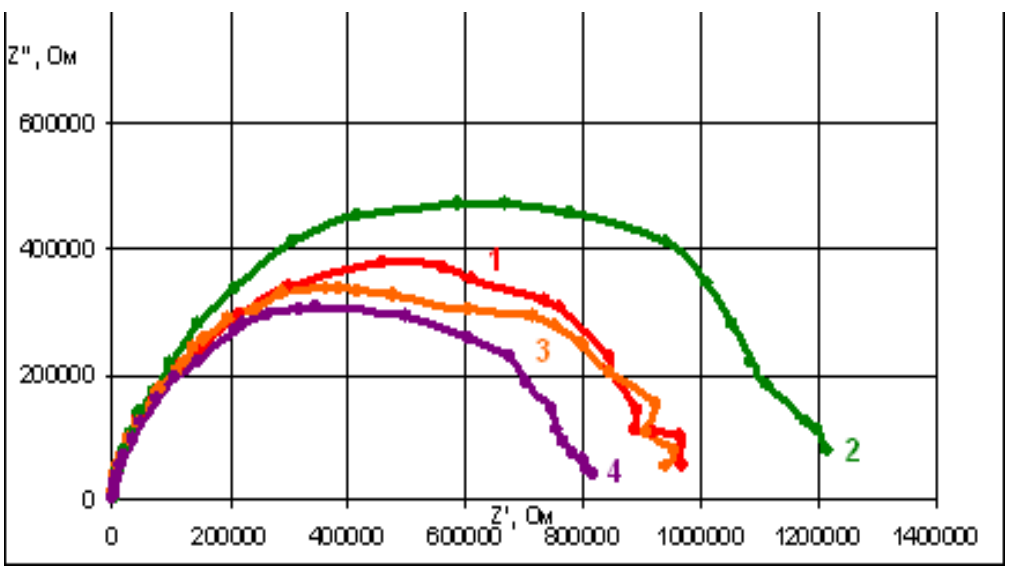

Figure 2. The hodograph kinetics of the impedance of the inert coating R-5095 on a platinum substrate after exposure to $3 \% \mathrm{NaCl}$ for: 1 - 30 days; 2 - 60 days; 3 - 130 days; $4-160$ days. 
As can be seen from the presented data (Figures 1,2), the impedance hodograph for an insulating coating (with inert filler) on an inert (Pt) substrate is a semicircle.

These forms of the hodograph and the Bode diagram allow, as a first approximation, to state that the only relaxation process is recorded in the system. This process is described by the simplest 3 -element equivalent circuit fairly accurately (Figure 1).

The characteristic frequency $5.7 \pm 1.0 \mathrm{kHz}$ of the Bode diagram maximum is typical of an electrolyte transfer process in the polymer matrix. But it should be noted that this maximum is rather stretched by frequency.

Table 1. Inert R-5095 coating electrochemical parameters on a platinum substrate after exposure to $3 \%$ $\mathrm{NaCl}$.

\begin{tabular}{cccc}
\hline \multirow{2}{*}{ Exposure time, days } & $\begin{array}{c}\text { Potential of Pt } \\
\text { substrate (SHE), } \mathbf{m V}\end{array}$ & \multicolumn{2}{c}{ Equivalent circuit parameters } \\
\cline { 3 - 4 } & 310 & $\mathbf{R 1 , ~ M \Omega}$ & CPE1-T, $\boldsymbol{\mu F}$ \\
\hline 7 & 340 & 0.82 & $4.6 \cdot 10^{-9}$ \\
14 & 364 & 0.87 & $3.8 \cdot 10^{-9}$ \\
30 & 418 & 0.94 & $6.4 \cdot 10^{-9}$ \\
60 & 589 & 1.18 & $6.0 \cdot 10^{-9}$ \\
130 & 564 & 0.89 & $6.0 \cdot 10^{-9}$ \\
160 & & 0.79 & $6.8 \cdot 10^{-9}$ \\
\hline
\end{tabular}

As can be seen (Table 1), quite an active change in the electrochemical parameters of an inert coating on an inert substrate is observed in the initial period (up to 30 days, i.e., at the impregnation stage). A certain stabilization of properties occurs at longer times but the values are rather variable.

When evaluating the results, we took into account that the coating protective properties and integrity were completely preserved during the entire exposure time (up to 160 days). No cracks, swellings or delaminations from the substrate were detected.

\subsection{Impedance of an insulating coating on a corrosion-active substrate (mild steel St3)}

As can be seen from the data below, the impedance hodograph and the Bode diagrams of an insulating coating on a corrosion-active substrate (St3) (Figures 3,4) are rather close to those on an inert (Pt) substrate (Figure 2) for up to 30 days (at the initial stage).

In this case the description can be carried out using the simplest 3-element equivalent circuit (Figure 3), as well as for the platinum substrate.

Thus, the only relaxation process with a characteristic frequency of $5.7 \pm 1.0 \mathrm{kHz}$ is detected during the initial stage of EIS studies (up to 30 days). This corresponds to the frequency of the same coating on the platinum substrate. 


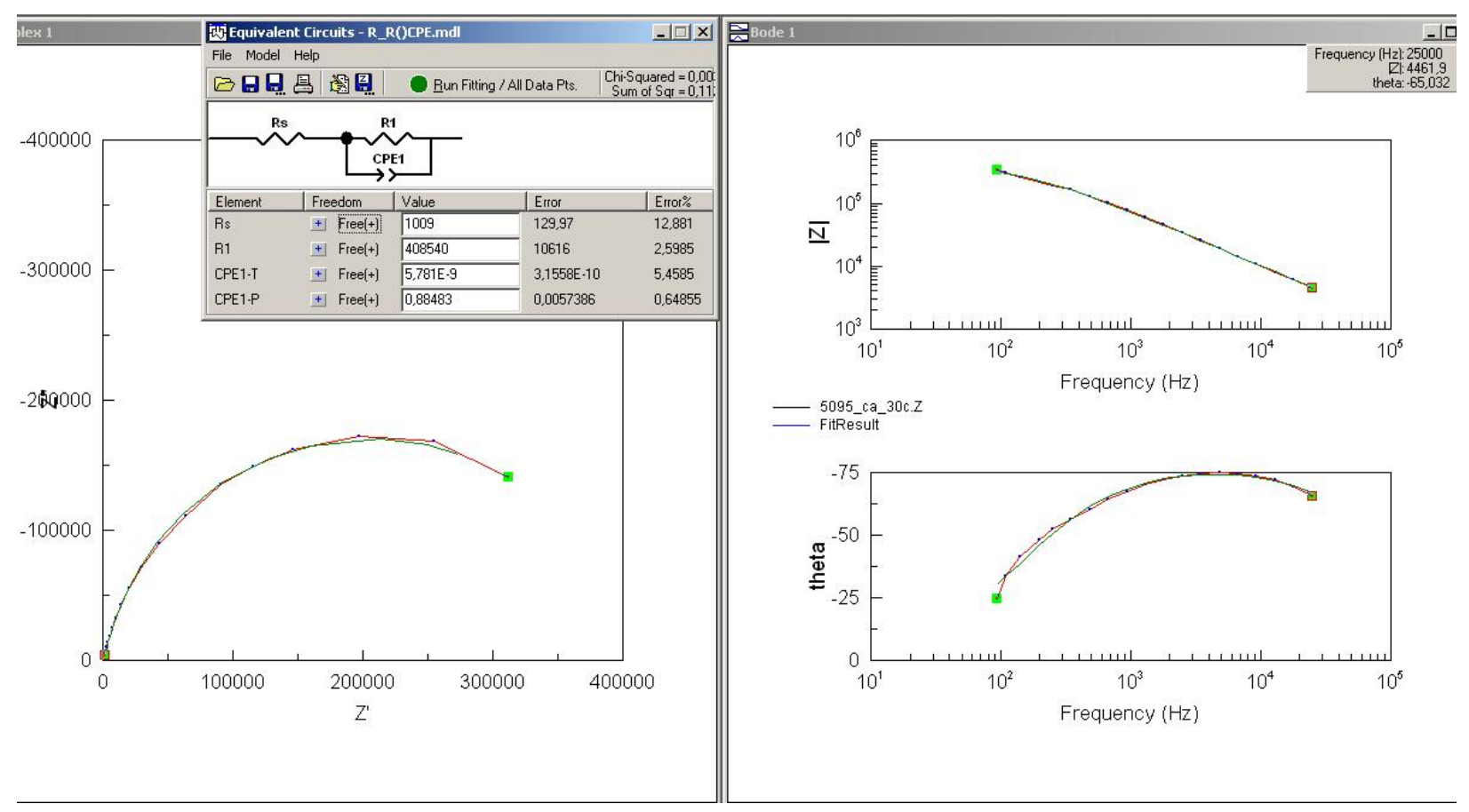

Figure 3. The hodograph and frequency dependences of the impedance of the R-5095 coating with an inert filler $\left(\mathrm{TiO}_{2}\right)$ on a mild steel (St3) substrate at the initial stage of exposure to $3 \%$ $\mathrm{NaCl}$ for 30 days.

With a further increase in exposure from 60 to 160 days, a qualitative change in the impedance hodograph shape (Figure 4) and frequency characteristics is observed on the corrosion-active St3 substrate. In addition to the HF process with a characteristic frequency of $6.7 \mathrm{kHz}$, a new LF process with a frequency of about $250 \mathrm{~Hz}$ (Figure 5) is recorded.

It is interesting to note that the Bode diagram maximum of the HF process for the insulating coating is less stretched by frequency on corrosion-active (St3) substrate than on inert $(\mathrm{Pt})$ substrate.

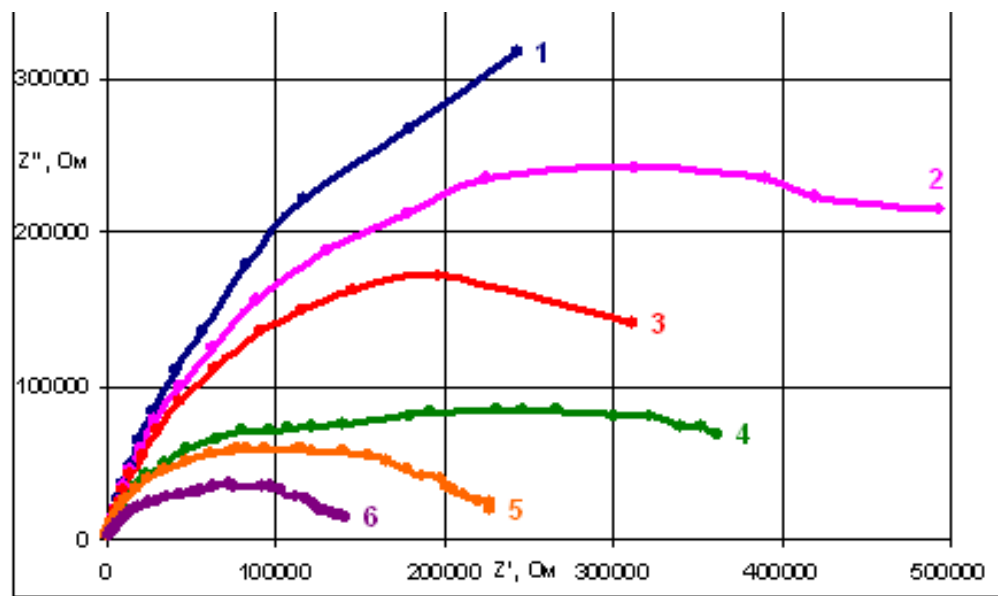

Figure 4. The hodographs of the impedance of the R-5095 coating on the mild steel substrate after exposure to $3 \% \mathrm{NaCl}$ for: $1-3$ days; $2-14$ days; $3-30$ days; $4-60$ days; $5-100$ days; 6 - 160 days. 
The second process has a low frequency and appears for the inert coating only on a corrosion-active mild steel substrate. This makes it possible to define it as under-coating corrosion of a mild steel substrate. This conclusion is supported also by the fact that this process is detected only for long times (60 days or more), when the medium penetrated to the substrate.

The description can be carried out using an equivalent circuit with two series R / $\mathrm{CPE}$ elements (Figure 5), because the processes of transfer and of corrosion under the coating are divided spatially.
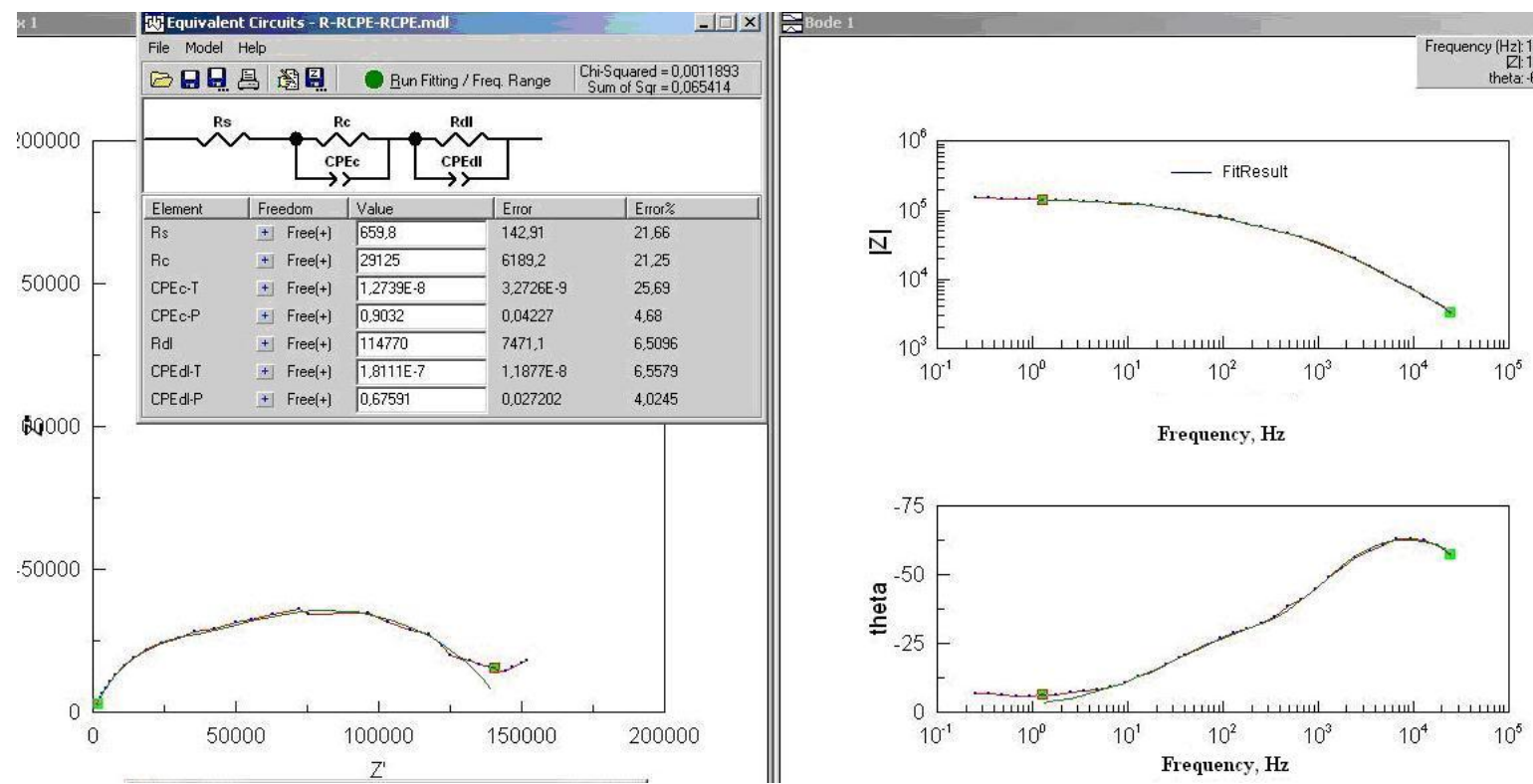

Figure 5. The hodograph and frequency dependences of the impedance of the R-5095 coating with inert filler $\left(\mathrm{TiO}_{2}\right)$ on a mild steel substrate after exposure to $3 \% \mathrm{NaCl}$ for 160 days. The Bode diagram maxima frequencies are $6.7 \mathrm{kHz}$ and $250 \mathrm{~Hz}$.


Figure 6. Graphic representation of the components of the hodograph (A) and the frequency dependence of the phase angle (B) for the R-5095 coating with inert filler $\left(\mathrm{TiO}_{2}\right)$ on a mild steel substrate after exposure to $3 \% \mathrm{NaCl}$ for 160 days. 1 - Experiment; 2 - HF component and 3 - LF component, calculated by the equivalent circuit. 
From Figure 6A it seems that the integral experimental dependence and the sum of the selected HF and LF components do not match in the zone of their intersection. But this seeming discrepancy is due to the fact that the centers of the HF and LF semicircles lie significantly below the $\mathrm{x}$-axis.

Table 2. Inert R-5095 coating electrochemical parameters on a mild steel substrate during exposure to $3 \%$ $\mathrm{NaCl}$.

\begin{tabular}{|c|c|c|c|c|c|}
\hline \multirow{3}{*}{$\begin{array}{l}\text { Exposure } \\
\text { time, days }\end{array}$} & \multirow{3}{*}{$\begin{array}{c}\text { Potential of } \\
\text { steel } \\
\text { substrate } \\
\text { (SHE), mV }\end{array}$} & \multicolumn{4}{|c|}{ Equivalent circuit parameters } \\
\hline & & \multicolumn{2}{|c|}{ HF process } & \multicolumn{2}{|c|}{ LF process } \\
\hline & & $R_{\mathrm{HF}}, \mathrm{M} \Omega$ & $\mathrm{CPE}_{\mathrm{HF}}, \boldsymbol{\mu F}$ & $R_{\mathrm{LF}}, \mathrm{M} \Omega$ & CPE-T $T_{L F}, \mu F$ \\
\hline 7 & 90 & 0.61 & $4.5 \cdot 10^{-9}$ & & \\
\hline 14 & -50 & 0.51 & $4.9 \cdot 10^{-9}$ & & \\
\hline 30 & -36 & 0.32 & $4.6 \cdot 10^{-9}$ & & \\
\hline 60 & -93 & 0.12 & $6.8 \cdot 10^{-9}$ & 0.29 & $2.0 \cdot 10^{-7}$ \\
\hline 160 & -100 & 0.03 & $13 \cdot 10^{-9}$ & 0.12 & $1.8 \cdot 10^{-7}$ \\
\hline
\end{tabular}

The values of active resistance and capacitance for the high-frequency process at mild steel (St3) are close to the parameters recorded on inert (Pt) substrate at the initial stage of the exposure (up to 7-14 days) (Tables 1 and 2).

The resistance of the coating on a mild steel ( $\mathrm{St} 3)$ is significantly lower than on platinum substrate, and the capacitance is higher for long immersion in media, and above mentioned discrepancy of the electrochemical parameters increases over time. Possible explanation, from our point of view, is the facilitation of transfer due to the appearance of additional charge carriers (soluble steel corrosion products) in the system with a corrosionactive substrate and (or) due to an increase in porosity due to local deformation of the coating by the resulting under-coating corrosion products.

Although the potential of the mild steel substrate under the inert coating decreases with time, it remains above the corrosion potential of unprotected steel $(-430 \mathrm{mV})$. This indicates a high insulating properties of the coating or a variation of the internal electrolyte composition (salt/water ratio) [3] in the coating compared to the external $3 \% \mathrm{NaCl}$ solution.

\subsection{Composite coating (insulating layer $+Z n$-rich primer) on an inert (Pt) substrate.}

The composite coating (Zn-rich primer + upper insulating layer) on an inert (Pt) substrate as well as the previously considered single-layer systems has a single relaxation process with a characteristic frequency of $5.7 \pm 1.0 \mathrm{kHz}$ at the initial stage (1-30 days), but at longer times the hodograph and frequency dependencies are the superposition of two processes: HF and LF (Figure 7, Table 3). 



A

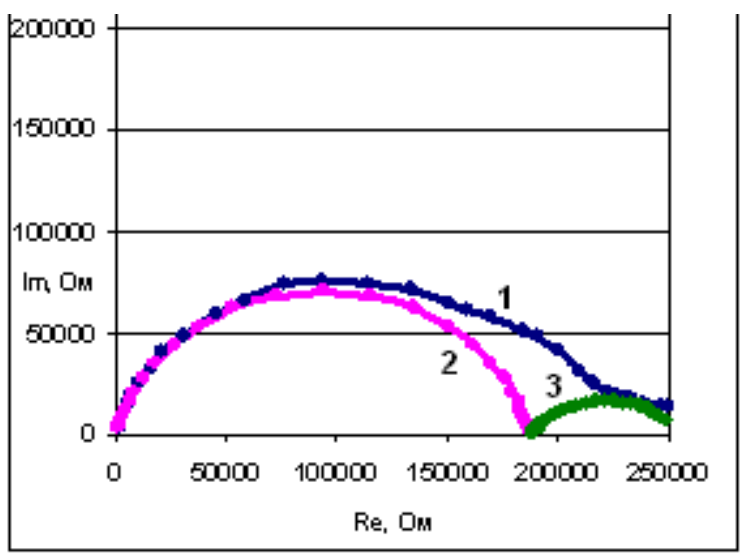

B

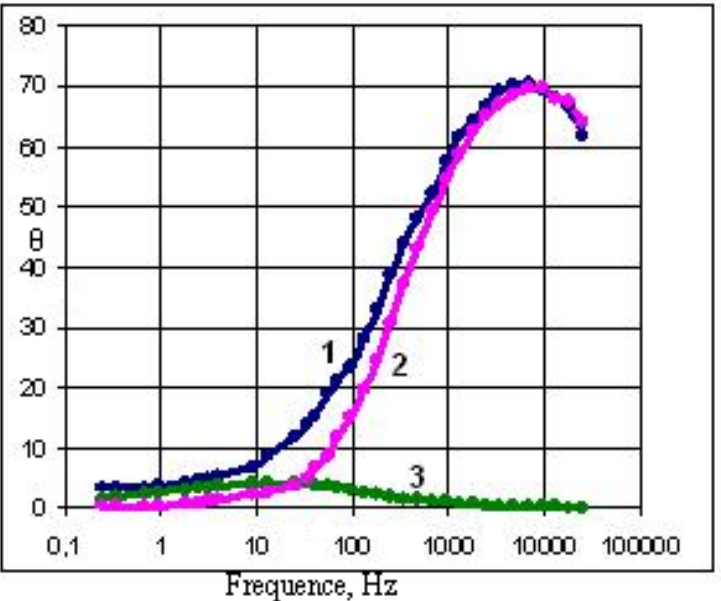

C

Figure 7. The hodograph and frequency dependencies of the impedance of a 2-layer coating M-017 + R-5095 on a platinum substrate after exposure to $3 \% \mathrm{NaCl}$ for 160 days (A). The Bode diagram maxima frequencies are $6.7 \mathrm{kHz}$ and $9.3 \mathrm{~Hz}$.

Graphic representation of the components of the hodograph (B) and the frequency dependence of the phase angle (C) after exposure to $3 \% \mathrm{NaCl}$ for 160 days. 1 - Experiment; 2 - HF component and 3 - LF component calculated by the equivalent circuit (Figure 7A). 
In the system considered, only $\mathrm{Zn}$ powder in the primer can corrode. So, the detected LF process can only be caused by Zn corrosion.

Since the processes in an upper inert insulating layer and in an inner primer layer containing $\mathrm{Zn}$ particles are divided spatially, the description also can be carried out using an equivalent circuit with two series of $R / \mathrm{CPE}$ elements (Figure 7A).

\subsection{Composite coating (insulating layer + Zn-rich primer) on a mild steel substrate (St3)}

There are two potential corrosion objects ( $\mathrm{Zn}$ filler in the primer and a corrosion-active steel substrate) in this system. However, the hodographs and frequency dependencies do not qualitatively differ from the two-layer system on an inert platinum substrate discussed above.

The only relaxation process with a characteristic frequency of $5.7 \pm 1.0 \mathrm{kHz}$ is recorded for this system at the initial stage of impregnation (1-30 days).

And there are two relaxation electrochemical processes in the system: high-frequency (HF) and low-frequency (LF) at large times (60-160 days).

The relaxation processes are divided spatially; it is reasonable to use an equivalent circuit with two series $R / C P E$ elements (Figure 8).

The calculated electrophysical characteristics for the composite coatings are summarized in the tables below (Tables 3 and 4).
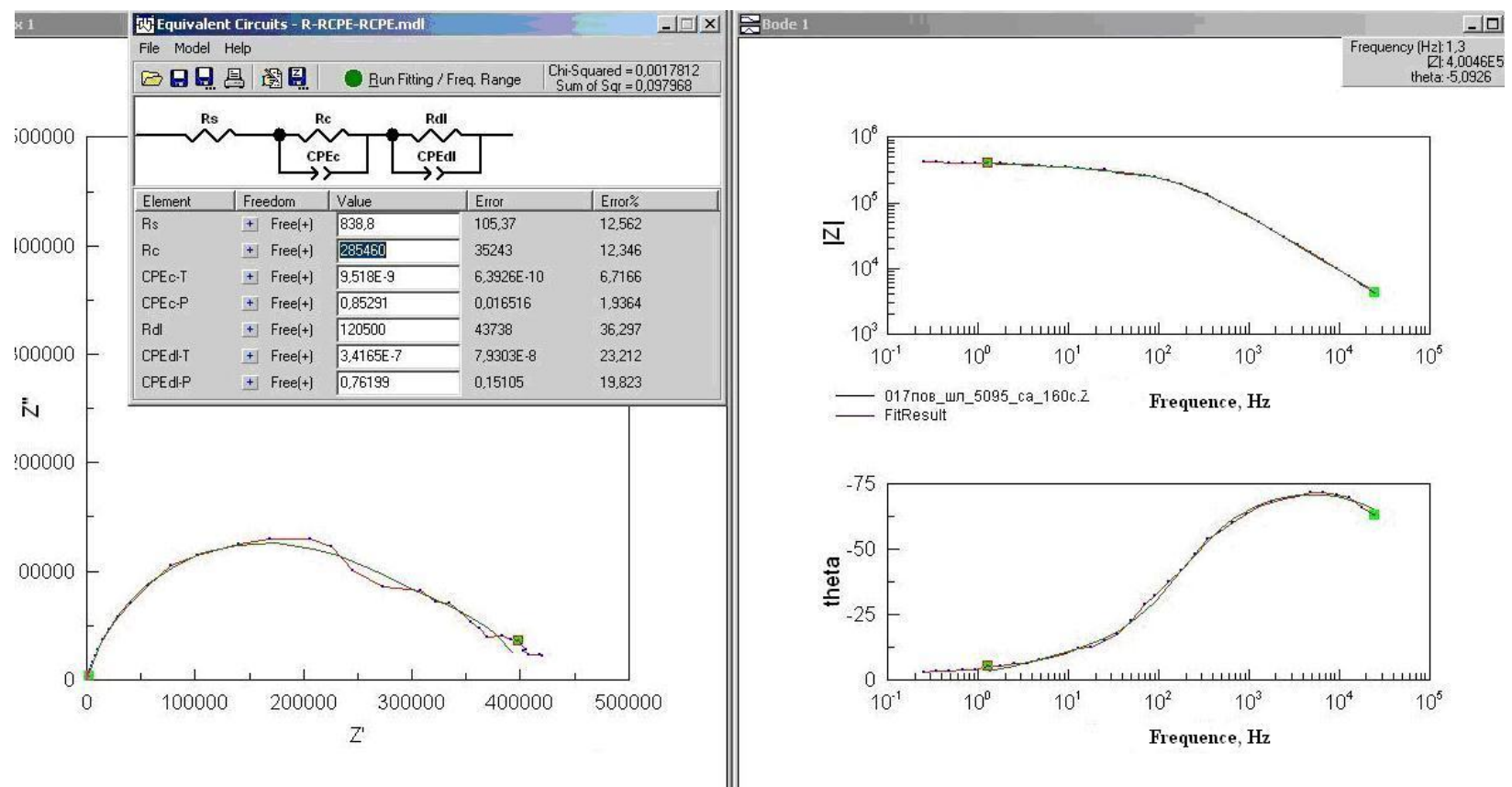




(B)

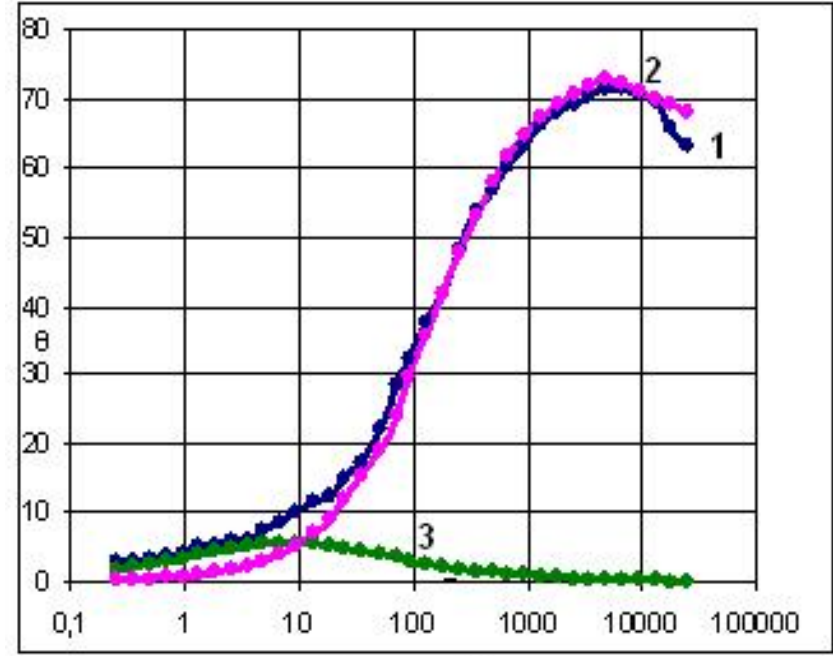

Frequency, $\mathrm{Hz}$

(C)

Figure 8. The hodograph and frequency dependencies of the impedance of a 2-layer coating M-017 + R-5095 on a mild steel substrate after exposure to $3 \% \mathrm{NaCl}$ for 160 days (A). The Bode diagram maxima frequencies are $4.8 \mathrm{kHz}$ and $9.32 \mathrm{~Hz}$.

Graphic representation of the components of the hodograph (B) and the frequency dependence of the phase angle (C) after exposure to $3 \% \mathrm{NaCl}$ for 160 days. 1 Experiment; 2 - HF component and 3 - LF component calculated by the equivalent circuit (Figure 8A).

The qualitative conclusion for 2-layer protective coatings can be seen from the data (Table 3):

- An impregnation process is slow for the coatings with an insulating top layer in the $\mathrm{NaCl}$ solutions (up to 30-60 days).

- The only HF process (the electrolyte transfer in the polymer matrix) is detected at the initial stage of impregnation ( $\leq 30$ days) in all cases.

- A low-frequency process appears on a mild steel (St3) substrate or in the presence of an inner layer with a protective $\mathrm{Zn}$ powder at longer times (> 60 days). It can be identified as an under- coating corrosion process. While there isn't low frequency process on an inert platinum substrate and high frequency process is the only.

- The resistances are quite close for the LF process in the case of composite coating on St3 and on Pt. These characteristics are also close to the values for an inert coating R-5095 applied on a mild steel substrate without primer. 
Table 3. Inert R-5095 coating and composite M-017 + R-5095 coating electrochemical parameters on a mild steel (St3) and a platinum $(\mathrm{Pt})$ substrates after exposure to $3 \% \mathrm{NaCl}$.

\begin{tabular}{|c|c|c|c|c|c|c|}
\hline \multicolumn{3}{|c|}{ Coating characteristics } & \multicolumn{4}{|c|}{ Equivalent circuit parameters } \\
\hline \multirow{2}{*}{ Coating } & \multirow{2}{*}{ Substrate } & \multirow{2}{*}{$\begin{array}{l}\text { Exposure } \\
\text { time, days }\end{array}$} & \multicolumn{2}{|c|}{ High-frequency process } & \multicolumn{2}{|c|}{ Low-frequency process } \\
\hline & & & $\mathbf{R}_{\mathrm{HF}}, \mathbf{M} \Omega$ & ${\text { CPE}-T_{H F}}_{H}, \mu F$ & $\mathbf{R}_{\mathrm{LF}}, \mathbf{M} \Omega$ & CPE-T $T_{L F}, \mu F$ \\
\hline \multirow{4}{*}{$\begin{array}{c}\text { Epoxy enamel } \\
\text { R-5095 }\end{array}$} & \multirow[b]{2}{*}{ Platinum } & 30 & 0.94 & $6.4 \cdot 10^{-9}$ & & \\
\hline & & 160 & 0.79 & $6.8 \cdot 10^{-9}$ & & \\
\hline & \multirow[b]{2}{*}{ Steel St3 } & 30 & 0.31 & $4.6 \cdot 10^{-9}$ & & \\
\hline & & 160 & 0.03 & $13 \cdot 10^{-9}$ & 0.11 & $1.8 \cdot 10^{-7}$ \\
\hline \multirow{4}{*}{$\begin{array}{c}\text { Zn-rich primer } \\
\text { M-017 + epoxy } \\
\text { enamel } \\
\text { R-5095 }\end{array}$} & \multirow[b]{2}{*}{ Platinum } & 30 & 0.46 & $8.8 \cdot 10^{-9}$ & & \\
\hline & & 160 & 0.13 & $8.3 \cdot 10^{-9}$ & 0.10 & $1.1 \cdot 10^{-7}$ \\
\hline & \multirow[b]{2}{*}{ Steel St3 } & 30 & 0.62 & $4.7 \cdot 10^{-9}$ & & \\
\hline & & 160 & 0.29 & $9.5 \cdot 10^{-9}$ & 0.12 & $3.4 \cdot 10^{-7}$ \\
\hline
\end{tabular}

Table 4. Characteristic frequencies of electrochemical processes according to the Bode diagram after the exposure of polymer coatings on steel and platinum substrates for 160 days in $3 \% \mathrm{NaCl}$

\begin{tabular}{cccc}
\hline \multirow{2}{*}{ Coating } & Substrate & $\begin{array}{c}\text { Characteristic frequencies of high-frequency (HF) and } \\
\text { low-frequency }(\mathbf{L F}) \text { processes, Hz }\end{array}$ \\
\cline { 3 - 4 } & & HF & LF \\
\hline Zn-rich primer M-017 & Steel St3 & $(12.9 \pm 2.0) \cdot 10^{3}$ & $(12.9 \pm 1.0)$ \\
\hline Epoxy enamel R-5095 & Platinum & $(5.7 \pm 1.0) \cdot 10^{3}$ & - \\
& Steel St3 & $6.7 \cdot 10^{3}$ & 250 \\
\hline $\begin{array}{c}\text { Zn-rich primer M-017 + } \\
\text { epoxy enamel } \\
\text { R-5095 }\end{array}$ & Platinum & $(5.7 \pm 1.0) \cdot 10^{3}$ & $(9.3 \pm 2.0)$ \\
\hline
\end{tabular}

The results of frequency analysis data (Table 4):

- The frequencies of the HF processes of mass transfer lie in a same range for all studied composite coatings on various substrates. Although, these frequencies vary slightly.

- The frequency of the LF process depends on the structure of the multi-layer coating and the type of substrate:

a. The LF process frequencies $(9.3 \mathrm{~Hz})$ of the composite coatings with a $\mathrm{Zn}$-rich primer and of an upper insulating layer are close to the frequency of a similar process in a Zn-rich primer applied on a mild steel substrate without an upper insulating layer $(12.9 \mathrm{~Hz})$. 
b. The LF processes frequencies are the same $(9.3 \mathrm{~Hz})$ for composite coatings with a $\mathrm{Zn}$-rich primer on St3 and Pt substrates for long exposure times. This allows us to conclude that corrosion of $\mathrm{Zn}$ powder is a leading Faraday process in both cases.

c. The structure of multi-layer coating is a factor determining the frequency of the LF process for coatings on a mild steel substrate. So the Faraday LF process is detected in composite systems with a Zn-rich primer at significantly lower frequencies $(9.3 \mathrm{~Hz})$ than at applying of an insulating coating only $(250 \mathrm{~Hz})$. This can be considered as evidence of a protective effect of the $\mathrm{Zn}$-rich primer on the mild steel substrate, not only at the initial stage, but also at long exposure times of $3 \% \mathrm{NaCl}$.

The results obtained show that the electrochemical impedance spectroscopy (EIS) is a highly informative method for monitoring the development of under-coating corrosion for the multilayer composite protective coatings with high electrical resistances. EIS allows making a certain contribution to the development of non-destructive corrosion testing for the protective coatings $[16,17]$.

EIS can be used to:

- obtain detailed quantitative information about the electrochemical properties of the "coating-substrate" system;

- evaluate the current stage of the process of interaction with the medium, the insulating properties and impregnation time;

- obtain information about the protective mechanism, including for coatings with several possible objects of under-coating corrosion.

\section{References}

1. T.N. Ostanina, Electrochemical behavior and physico-chemical properties of metalcoated coatings, Dissertation for the degree of doctor of science in the specialty 02.00.05-electrochemistry, Ekaterinburg, 2003, p. 226 (in Russian).

2. V.A. Golovin, S.A. Dobriyan and V.B. Lukin, Growth of the insulating ability of the coatings with active solid-phase and inhibitory additives, Korroz.: Mater., Zashch., 2018, no. 6, 23-31 (in Russian).

3. ISO 12944-5, Varnishes and Paints. Corrosion protection of steel structures by protective coating systems. Part 5: combinations of protective paints.

4. V.A. Golovin, A. B. Il'in, V.A. Shchelkov, S.A. Dobriyan, S.A. Tyurina and I.I. Reformatskaya, Concept of composite polymer coatings for oil and gas environments, Korroz.: Mater., Zashch., 2015, no. 1, 14-22 (in Russian).

5. V.A. Golovin, A.B. Il'in and A.D. Aliev, Mass transfer of phosphate-based corrosion inhibitors in epoxy coatings, Korroz.: Mater., Zashch., 2018, no. 8, 18-24 (in Russian). 
6. A.B. Ilyin, V.A. Shchelkov, V.A. Rabinkov and V.A. Golovin, Water-diluent epoxy materials for protection of building structures under adverse conditions of application, Praktika protivokorrozionnoi zashchity, 2018, 88, no. 2, 15-22 (in Russian).

7. C. Gabrielli, Use and application of electrochemical impedance techniques, Farnborough, 1990, p. 78.

8. F. Brambilla, E. Campazzi, D. Sinopoli, P.-J. Lathiere, P. Cote, N. Pebere, E. Lebon, C. Barbe and A. Noble, Accelerated corrosion testing: a prodictive tool, in: Theses of The Annual Congress of the European Federation of Corrosion (EUROCORR 2018), Cracow, Poland, September 9-13, 2018, 120935.

9. N.A. Poklonsky and N.I. Gorbachuk, Fundamentals of impedance spectroscopy of composites, Minsk, BGU, 2005, 130 pp. (in Russian).

10. ISO 16773-1,2,3,4:2007, Electrochemical impedance spectroscopy (EIS) on highimpedance coated specimens.

11. M. Curioni, F. Scenini, T. Monetta and F. Bellucci, Correlation between electrochemical impedance measurements and corrosion rate of magnesium investigated by real-time hydrogen measurement and optical imaging, Electrochim. Acta, 2015, 166, 372-384.

12. C. Liu, Q. Bi, A. Leyland and A. Matthews, An electrochemical impedance spectroscopy study of the corrosion behaviour of PVD coated steels in $0.5 \mathrm{~N} \mathrm{NaCl}$ aqueous solution: Part II.: EIS interpretation of corrosion behaviour, Corros. Sci., 2003, 45, no. 6, $1257-$ 1273.

13. C.G. Oliveira and M.G.S. Ferreira, Ranking high-quality paint systems using EIS. Part I: intact coatings, Corros. Sci., 2003, 45, no. 1, 123-138.

14. G. Bierwagena, D. Tallman, J. Li, L. He and C. Jeffcoate, EIS studies of coated metals in accelerated exposure, Progr. Org. Coat., 2003, 46, no. 2, 149-158.

15. V.A. Golovin, S.A. Dobriyan, V.B. Lukin and K.V. Kosinenko, To the question about the choice of equivalent circuits to describe the electrochemical impedance spectra of Zn-filled polymer primers and coatings, Korroz.: Mater., Zashch., 2016, no. 9, 1-9 (in Russian).

16. A. Lutz, I. De Graeve and H. Terryn, Non-destructive in-situ characterization of microcapsules and self-healing coatings using confocal Raman spectroscopy, in Proc. EUROCORR-2014, 2014.

17. G. Sundararajan and R. Rebak, Electrochemical behaviour of protective coatings in chloride solutions, in Proc. EUROCORR-2014, 2014. 